\title{
Modelling population structure in the context of urban land use change in Europe
}

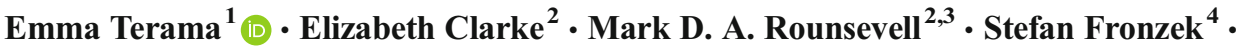 \\ Timothy R. Carter ${ }^{4}$
}

Received: 20 September 2016 / Accepted: 22 June 2017 / Published online: 8 July 2017

(C) The Author(s) 2017. This article is an open access publication

\begin{abstract}
Population structure and dynamics are important drivers of land use. In this article, we present the methods and outcomes of integrating population projections across multiple spatial scales with an urban growth model. By linking shared socioeconomic pathway (SSP)-specific national population projections to present-day population distributions at a sub-national scale, we describe a downscaling approach that provides input into a regional urban growth (RUG) model for Europe. The allocation of population acts as a key driver for residential urban demand especially in the SSP5-based scenario, and therefore regional (sub-national)
\end{abstract}

Electronic supplementary material The online version of this article (doi:10.1007/s10113-017-1194-5) contains supplementary material, which is available to authorized users.

Emma Terama

emma.terama@environment.fi; emma.terama@ymparisto.fi

Elizabeth Clarke

elizabeth.clarke@ed.ac.uk

Mark D. A. Rounsevell

mark.rounsevell@ed.ac.uk

Stefan Fronzek

stefan.fronzek@ymparisto.fi

Timothy R. Carter

tim.carter@ymparisto.fi

1 Environmental Policy Centre, Finnish Environment Institute (SYKE), Helsinki, Finland

2 School of GeoSciences, University of Edinburgh, Edinburgh, UK

3 Land Use Change Research Group, Karlsruhe Institute of Technology, Garmisch-Partenkirchen, Germany

4 Climate Change Programme, Finnish Environment Institute (SYKE), Helsinki, Finland urban growth. Sub-national population trends can deviate strongly from national averages stemming from current population age structures: this creates different urban land use patterns and demand for artificial surfaces. We see strong population dependence in the regional development of urban areas across Europe, and the effects caused by age structure and sub-national population dynamics.

Keywords Climate change $\cdot$ Demography $\cdot$ Land use . Population $\cdot$ Projection $\cdot$ SSP $\cdot$ Urban

\section{Introduction}

Population structure and dynamics are important drivers of land use in Europe. Both population and land use change are modelled extensively, but separately (Rogers 1986; Bongaarts and Bulatao 2000; Veldkamp et al. 2001; Cohen 2003; Rounsevell et al. 2012; KC and Lutz 2014; Rounsevell et al. 2014), which is a limitation of current approaches. By being considered in combination, modelling of population and land use change would advance knowledge of societal responses to global change research, especially with respect to impacts, adaptation and vulnerability to climate change (CCIAV) (see, for example Riebsame et al. 1994; Verburg et al. 2004; Kriegler et al. 2012).

Europe is a largely urbanised region with $74 \%$ of the entire population living in cities, as compared to $54 \%$ for the world or $69 \%$ for Eastern Europe (United Nations 2014). Demographic change is, like other biophysical factors, important, as it can drive sub-national regions in different directions when compared to national (or continental) trends (Veldkamp et al. 2001; Lambin and Meyfroidt 2010), a consequence of, especially, fertility and migration. Understanding the role of population dynamics as a driver of urban land use change is essential (Reginster and Rounsevell 2006), such as in globally 
experienced population growth and locally manifested increases in artificial surface demand.

Climate change impacts, within regions, will depend on complex interactions between the climate system, ecosystems (natural and built) and socioeconomic systems (e.g. Carter et al. 2016). Information on regional population size and age structure is fundamental for understanding both society's exposure and vulnerability to climate change impacts as well as human influences on ecological and other natural systems. These effects can be investigated using regional CCIAV models in combination with integrated scenarios of climate and socioeconomic development (e.g. Harrison et al. 2013).

Alternative scenarios are a commonly used tool for exploring uncertainty for future societies under the influence of a changing climate (Jones et al. 2014). Future socioeconomic development is, in this paper, characterised by the shared socioeconomic pathways (SSPs): a set of global-scale qualitative storylines with commensurate quantifications around various combinations of socioeconomic conditions and trajectories that create challenges to greenhouse gas mitigation and/or climate adaptation (Moss et al. 2010, Kriegler et al. 2012; O'Neill et al. 2014, 2015; van Vuuren and Carter 2014; van Ruijven et al. 2014). Each SSP has a distinctive national-level population development pathway, with assumptions made around the demographic variables fertility, mortality and migration (KC and Lutz 2014; Wittgenstein Centre 2015). Here, we concentrate on the four scenarios: SSP1, SSP3, SSP4 and SSP5 (Fig. A1, annex).

The SSPs have been given descriptive names: sustainability — taking the green road (SSP1); regional rivalry—a rocky road (SSP3), inequality - a road divided (SSP4) and fossilfuelled development — taking the highway (SSP5). These narratives all describe, with slightly different outlooks, thematic indicators on (i) demographics, (ii) human development, (iii) the economy and population's lifestyle, (iv) policies and institutions (excluding climate policies), (v) technology and (vi) the environment and natural resources (O'Neill et al., 2015). The predominant features of the 'basic SSPs' 1, 3-5, are outlined in the annex: Box 1 and Fig. A1.

The scales of the global SSP narratives and their quantifications cannot always readily be reconciled with developments at sub-national scales that may be of interest for CCIAV analysis (Absar and Preston 2015). Therefore, a central aim of this paper is to bridge the gap between quantifications of population at a national scale or coarser and the pattern and structure of the population at sub-national scales that are crucial for understanding urban land use. An approach is taken to link two specific systems, namely the population system and the urban land use system. We describe the data and methods used for both models, their integration and the outcomes. The process concentrates on climate change impacts and adaptation with shared socioeconomic pathways as summarised in Fig. A1. In particular, we will investigate the changes in the urban land use arising from considering how age structure and age-dependent preferences drive residential mobility and what the effect of considering high-resolution spatial scales is. These aspects together comprise the unique population structure and dynamics viewpoint that, as we will see, has a major impact on urban land use change.

\section{Data and methods}

The inclusion of demographics within finer resolution, thematic (age) and spatial (regional) modelling frameworks requires linkages between national-scale scenario modelling and more detailed (regional) demographic descriptions. Such a link was established, in this research, by downscaling agespecific national population projections (described by the SSP scenarios) with age-specific distributions for spatially explicit, sub-national administrative units $\left(\mathrm{NUTS}-2^{1}\right.$ ). This procedure was required to link age-specific population projections to a regional urban growth (RUG) model for Europe.

SSP-specific population projections, from 2020 to 2100 , at the national scale for 5-year age intervals across Europe were obtained from the Wittgenstein Centre (2015) database that hosts the most recent version of the population component of the SSP-database (IIASA 2012). At the sub-national (here: regional) scale, current age-specific demographic data were obtained from Eurostat (2015) for the baseline year of 2010 (using the 2010 NUTS-2 administrative boundaries). Hereafter, the NUTS-2 geographies are referred to as 'regions' following Eurostat terminology.

The downscaling architecture made use of the SSP-specific national level population projections, as well as the Eurostat (2015) data on the distribution of age groups across regions of Europe in 2010. Downscaling processes assumed that (i) there is no variability in demographic (age-group) change at or below the NUTS-2 level (i.e. population change by age is uniformly distributed across a country), and (ii) sub-national migration cannot occur between the NUTS-2 regions. Population migration is encompassed (at a broad-scale) in the modelling of future population demographics under the SSP scenarios (O’Neill et al. 2015) (Table A1, annex) and are therefore included in the Wittgenstein Centre (2015) population projections.

Given that the age-group specific population change was treated as constant (spatially invariant) across all regions within a country, the contribution (share) of a region to the national total, for a specified age group, was consistent across scenario timesteps. At the 2010 baseline, regions have different demographic

\footnotetext{
${ }^{1}$ The NUTS (nomenclature of territorial units for statistics) is a hierarchical system for the division of the economic territory of the European Union (Eurostat 2011). NUTS-2 units are a hierarchical classification between NUTS-1 (the coarsest spatial resolution) and local administrative units (LAU-2) (the finest spatial resolution).
} 
profiles, i.e. the size (and significance) of each age category within the region differs. Thus, under future scenarios, age groups will change at different rates as a function of the age group-specific scenario definitions. Consequently, the contribution (share) of an age-group to the total regional population can feasibly change from one time step to the next. For example, within regions that project an ageing population, the relative importance of the retired age groups (to the total population) will increase.

The national, SSP scenario population trajectories are dependent on assumptions about the demographic variables fertility, mortality and migration. For this purpose, the countries were divided into two sub-categories "low fertility" and "richOECD" (KC and Lutz 2014). Table A1 gives the demographic assumptions used in the SSP population projections (Wittgenstein Centre 2015) and the (modelled) countries in each category.

The downscaling was carried out for all European countries for which data were available. This resulted in a set of 30 countries (of which one was absent from the Wittgenstein Centre database ${ }^{2}$ ) and 277 NUTS-2 regions. Table A2 (annex) gives a list of the countries and their associated NUTS-2 regions and codes.

The downscaling was implemented at a thematic resolution of six age groups: (i) $0-14$ years, (ii) $15-29$ years, (iii) 30 49 years, (iv) 50-64 years, (v) 65-74 years and (vi) greater than 75 years. These were defined to represent distinct life cycle stages. Life cycle stage has been identified as a predominant factor in defining the residential location of an individual/household, with a need to increase/decrease property size identified as a fundamental driver of residential mobility (Fontaine and Rounsevell 2009; Fontaine et al. 2014).

\section{RUG—regional urban growth model}

Downscaled population demographics are a key input to RUG: a pan-European, land use model that explores trends in the driving forces of future urbanisation (artificial surfaces) through socioeconomic scenarios. RUG (Fig. A2, annex) applies demographic information at a regional (NUTS-2) level to model how a changing population might influence the demand for (required extent of) artificial surfaces. RUG applies the concept of life cycle stage influencing the residential preferences of individuals/households to determine how future population change, across the age groups specified, affects demand for three residential and one non-residential artificial surface types (Fig. A3, annex). Published, national scale estimates (Eurostat 2016a) of the working-age population resident within cities, suburban and rural areas are used to inform baseline residential preferences. The residential preferences of children $(0-14$ years) are linked to those of their parents. Consequently,

\footnotetext{
${ }^{2}$ Liechtenstein (single NUTS-2 unit: LI00) was missing from the Wittgenstein (2015) database, but given its small size and relative similarity to surrounding areas (in terms of population characteristics), the rate of demographic change was taken from AT34 in neighbouring Austria. Liechtenstein's baseline (2010) population structure was obtained from Eurostat (2015).
}

children are distributed to residential types as a function of the mother's (15-29 or 30-49) age group. The relative distribution, at the baseline, is informed by the regional scale birth rate records (Eurostat 2016b). The optimisation of residential preferences, from a national to regional scale, is fully described in in the paper by Terama et al. 2017 (Terama E, Clarke E, Rounsevell MDA, Cojocaru C, Cojocaru G (2017) A panEuropean regional urban growth model for cross-sectoral climate change impact modelling, in press).

For a given scenario (and time-step), RUG distributes the age groups of each region across a set of preferred residential types. Preferred residential types are a function of the age group, the scenario being considered and the baseline (region specific) description of the population's residential preferences. The residential area required to house and support the total population is then calculated based on population size and an estimate of the (scenario-defined) population density. Non-residential (industrial) expansion is defined separately. RUG assumes that the population reside in their preferred residential type. Demand will be met, by artificial surface expansion, to achieve these preferences. Modelling procedures do not 'fill' the existing urban fabric prior to determining if new artificial surface development is required. Where the estimated extent (demand) for any artificial surface type exceeds its current extent (as at the preceding time-step), the model will 'develop' new artificial surfaces across an underlying $10^{\prime}$ latitude/longitude grid. The expansion of each artificial surface type is spatially allocated to cells as a function of (a) the spatial autocorrelation between artificial surface types and (b) societal location preferences.

Residential preference modelling, within RUG, estimates the demographic profile of each residential type. This population is spatially disaggregated to the $10^{\prime}$ modelling grid (i) as a function of the current artificial surface profile of each cell and (ii) under the assumption that the population, for each residential type, lives at a homogenous density.

Given the rarity with which artificial surfaces are converted, at a large-scale, to alternate land use types, RUG assumes that existing artificial surfaces are static. Consequently, it is viable for the population densities of existing residential areas to decrease, replicating (a) processes of artificial surface abandonment; (b) increased urban green space and/or (c) the 'gentrification' of city areas (living more spaciously).

Parameterisation of RUG was based on a set of European storylines (Kok \& Pedde 2016), consistent with the SSPspecific population projections (Wittgenstein Centre 2015). Urban aspects of the European storylines (Fig. A4, annex) were translated, through stakeholder engagement and expert judgement, into modelling parameters (Fig. 1), which control both the distribution of the population across residential types and artificial surface demand. These parameters influence the extent and characteristics of future urbanisation. The full RUG parameterisation is described in Fig. A5 (annex). 
Fig. 1 RUG parameterisation in the context of the European SSP scenarios: parameters that influence artificial surface demand are to scale and represent the projected scenario-specific change

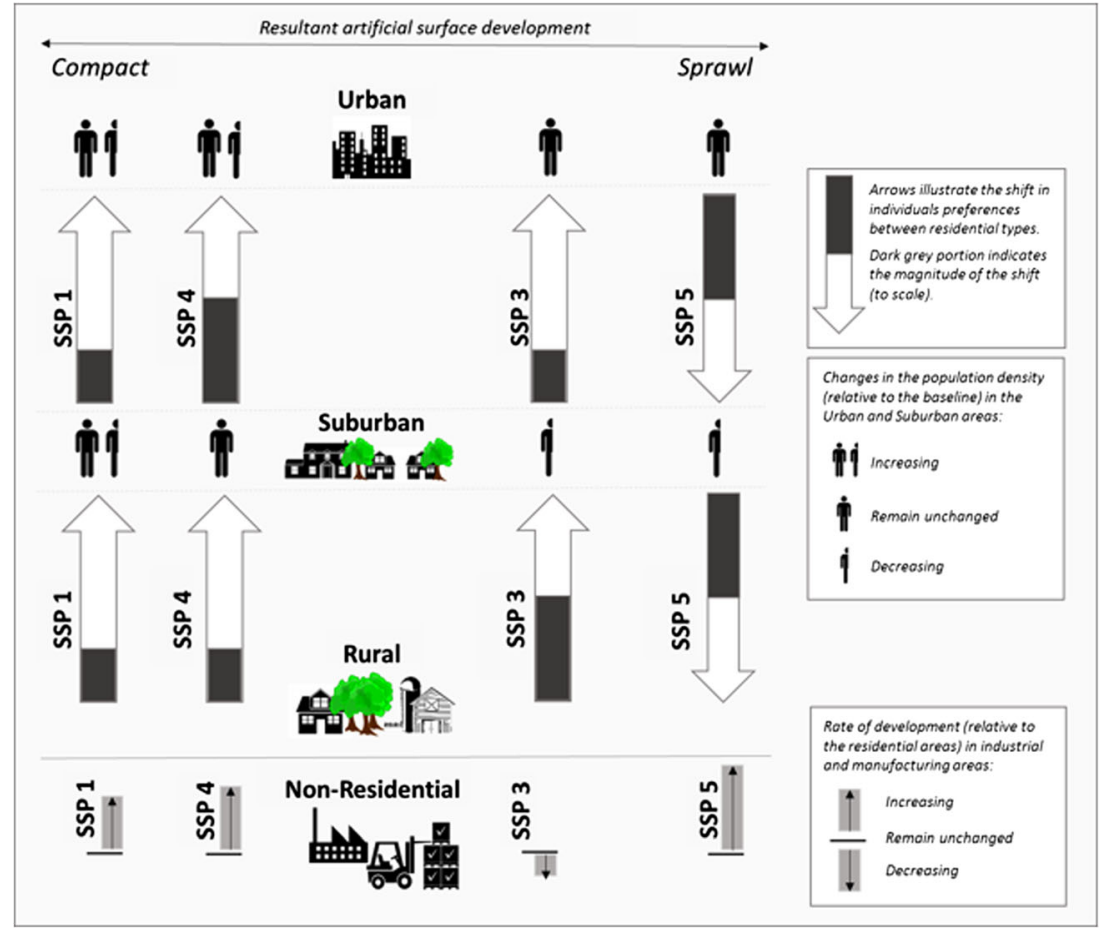

\section{Results}

\section{Population structure}

Figure 2 gives the country-specific population change rates, by age group, for the entire projection period for SSP1 (Sustainability). Rates of change are calculated as a ratio, from the baseline, where a value of one indicates no change and values greater/less than one an increasing/decreasing population trend, respectively. It is evident that change rates vary substantially, by age group, both within (intra-) and between (inter-) countries. The SSP1 socioeconomic scenario is characterised by an increasing but also an ageing population (significant growth of the population within the age-group 75+). For example, Portugal (PT) has declining populations within the $0-49$ years age groups, in contrast to the older age groups whose rates increase across the time period; up to a fourfold increase is predicted for the 75+-year age-group.

At the baseline, regions have different demographic profiles. Age groups, within a region, change at different rates as a function of the scenario and time-step being considered. Consequently, the total population within a region at a specified time-step is a function of (i) the size of each age group at the baseline and (ii) the rate of change projected for each age group. Then, also the rate of change of the total population between time-steps is region specific. Such region-specific change is demonstrated (Fig. A6, annex) for Portugal where, for example, in SSP3 a declining population trend for PT11 (Norte), PT17 (Lisboa) and PT16 (Centro Portugal) contrasts with the relatively static total population (and little overall change) observed in PT18 (Alentejo) and PT15 (Algarve).

\section{Population growth}

Europe-wide regional rates of change for the total populations are plotted up to 2100 under SSP1 (Fig. 3). This figure expresses, per time-step, the within-country, regional variability in total population change (as exemplified by Portugal (PT), Fig. A6) as a boxplot, a graphical summary of the distribution, central tendency and variability observed. Variance is given by the scale of each plot relative to the y-axis. The scenariospecific trend, in terms of the total population change, is visible in the overall slope of the curves and follows the demographic assumptions in KC and Lutz (2014): there is a clear differentiation between the rich-OECD (typified by increasing total populations, e.g. PT, UK) and low-fertility countries (typified by decreasing total populations, e.g. Bulgaria (BG), Romania (RO)). The rate of change in the total population (Fig. 3) is expressed as a ratio relative to the baseline, a value of one indicating no change. Where the boxplot sits above or below the dashed (no change) line, regions are predicted to increase or decrease, respectively, in terms of their overall population. Plots straddling the dashed line demonstrate that it would be incorrect to assume that (i) all regions within a country have the same general (increasing/decreasing) population trend, and (ii) the population trends of all regions, in terms of their total population, follow generalised country trends. 


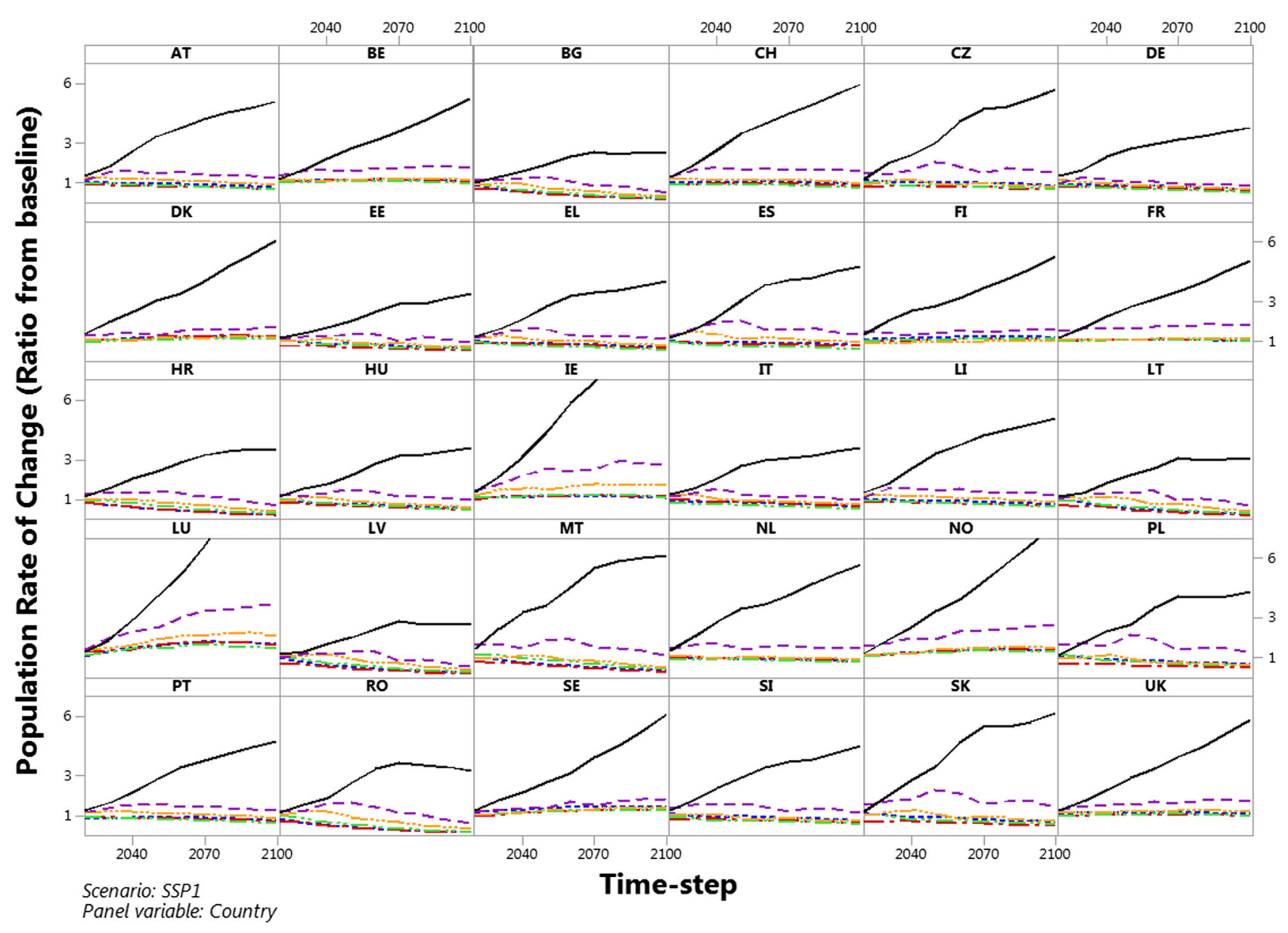

Age-Group

0-14 years

15-29 years

$30-49$ years

50-64 years

65-74 years

$75+$ years

Fig. 2 Change in population by age and country for SSP1

\section{Regional variation}

More detailed regional variability in the rates of total population change is described in Fig. A7 (annex) for each SSP. Here, the standard deviation is used as an indicative descriptor of the spread of total population change rates across the regions within a given country for a given time period. Plotting the standard deviations allows countries to be broadly compared in terms of their overall regional variability, although care of interpretation is required given the limited and varying number of regions within/between countries. From this figure, it is evident that Spain (ES), Portugal (PT) and Norway (NO) are characterised by high regional variability (as seen in their positions at the top of all plots). Conversely, Hungary (HU), Germany (DE) and Denmark (DK) hold many of the lowest positions. The countries at the bottom of the figures have the smallest standard deviation in their total population change, indicating that sub-national population change is roughly equal at the scale of regions (note that the standard deviation gives no information on the direction or consistency in the direction of change). Conversely, countries at the top have high variability in their total population change rates at a regional scale, i.e. within those countries, some regions are projected to change (grow or shrink) significantly faster than others.

In SSP1 and SSP5 (Fig. A7) within-country (regional) variability tends to increase over time. These increases are a function of the population trends, particularly focussed in a subset of age groups (cf. Fig 2), magnifying the differences in the total population (and therefore population change rate) of contrasting regions. SSP3 (Fig. A7) shows a marked decrease in variability across all countries, when compared to other SSP scenarios, demonstrating convergence (as opposed to the divergence observed in SSP1 and SSP5) in the between-region rates of change for SSP3 between 2020 and 2100. This reflects regional convergence between differing baseline demographic profiles enabled by the specific population assumptions underpinning SSP3: the regional convergence stems from convergence in rates of change across the age groups in SSP3 (not shown). This can be explained by the demographic 


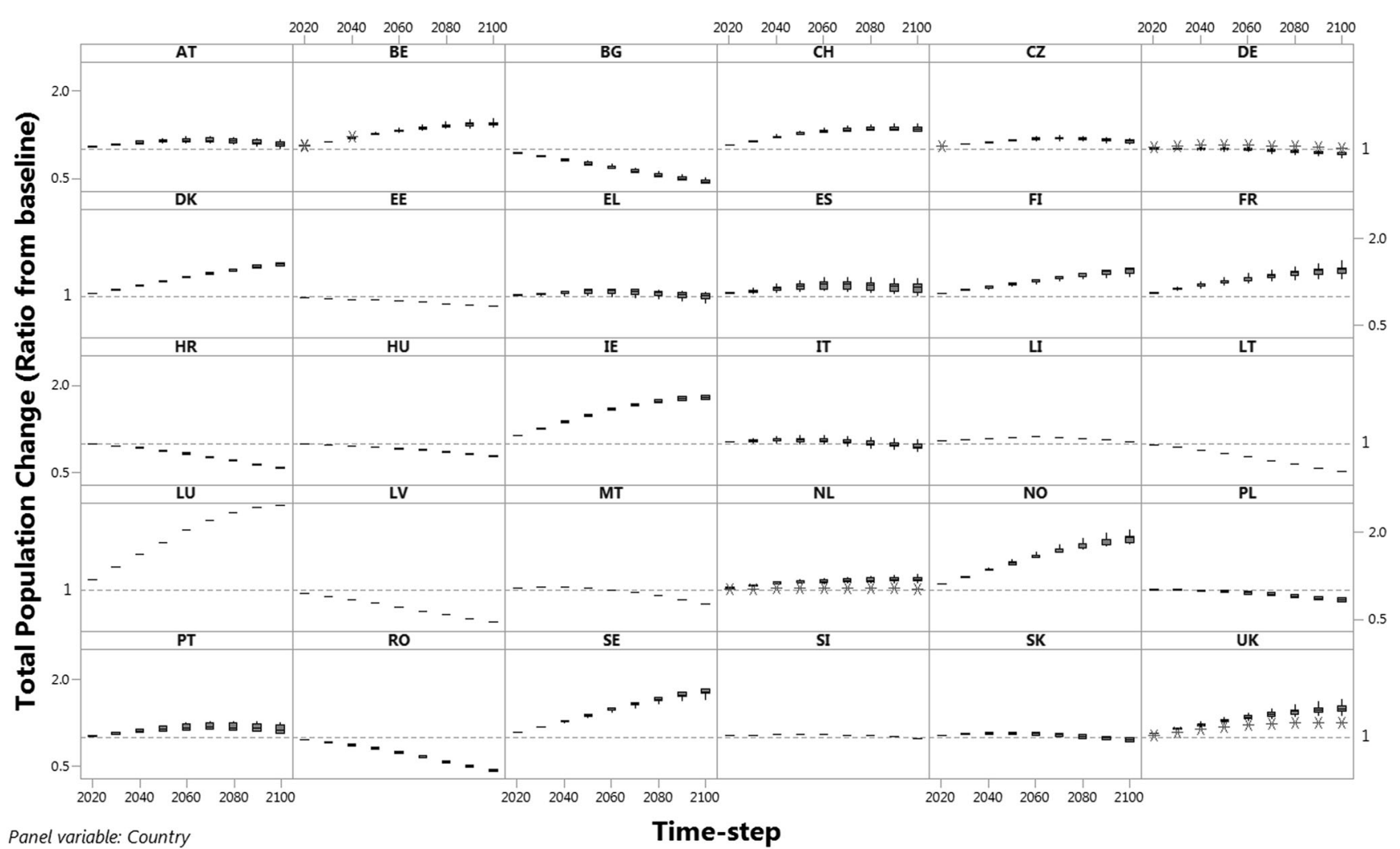
Scenario: SSP1

Fig. 3 Boxplots of regional (NUTS-2) scale total population change for SSP1. Regions are aggregated to their constituent countries. Notes: variance in the total population change determines the scale of the y-axis. Each region within a country contributes to each time point in the plot. Lines with star show outliers (On boxplots, Minitab uses an asterisk (*) symbol to identify outliers. These outliers are observations that are at least 1.5 times the interquartile range (Q3-Q1) from the edge of the box. See http://support.minitab.com/en-us/minitab/17/topic-library/basicstatistics-and-graphs/graph-options/exploring-data-and-revising-graphs/ identifying-outliers/) (if any) to the national trend. Rates of change are expressed relative to one (which indicates no change). Countries have varying numbers of regions: care of interpretation is required in the presence of a limited number of NUTS-2 (cf. Table A2)

shown), that is, the population as a whole and by age is relatively evenly distributed across the NUTS-2 units. This overarching national picture obscures variability in the demographic structure of the regions, a subset of which is illustrated in Table A3 (annex). This subset was selected to highlight regional variability.

The region UKI1 (Central London) is distinct since it is characterised by a higher than average proportion of children (0-14 years) and working-age adults (15-29 and 30-49 years), as opposed to the older 65-75+ age groups. Conversely, the region UKJ2 (Surrey, East and West Sussex) contains a high proportion of the total population, (i.e. is densely populated) but all age groups are relatively equally represented. Finally, region UKG2 (Shropshire and Staffordshire) is sparsely populated but, again, relatively equally populated by all age groups.

The application of uniform (national level) rates of age group-specific change to these exemplar regions, under SSP1, highlights their differing results in terms of (i) total population (Fig. 4a), and (ii) rate of change trajectories (Fig. 4b). Despite UKG2 and UKJ2 having distinctly different 

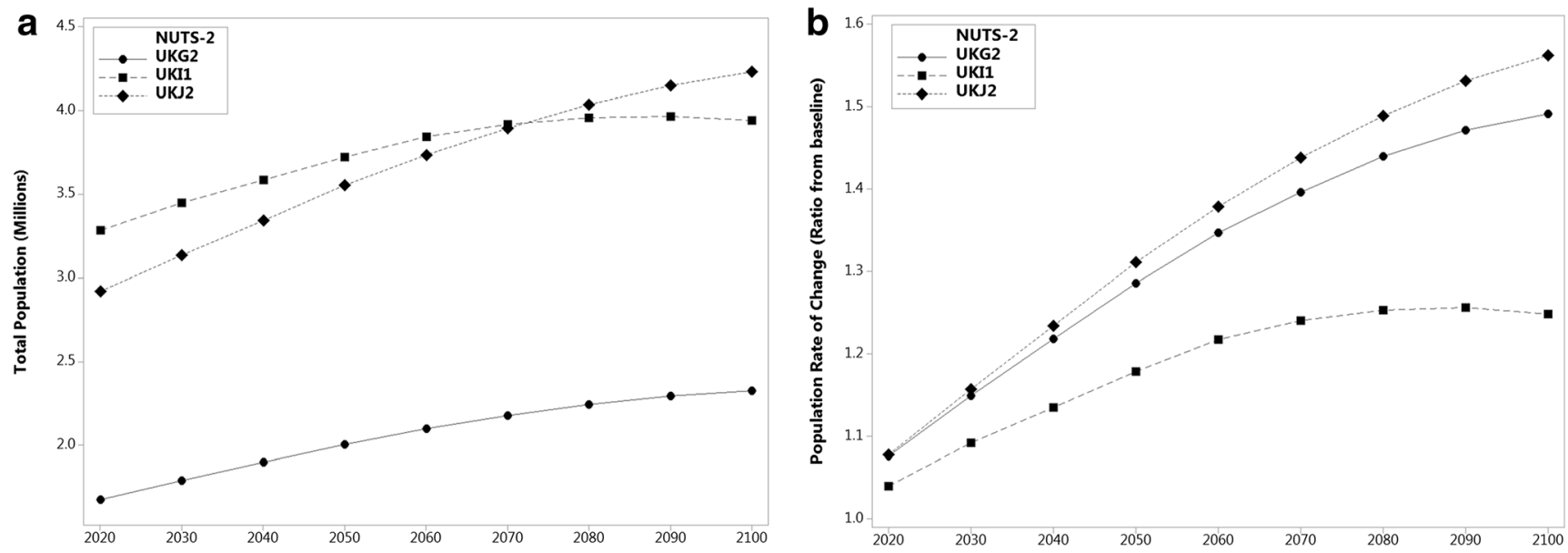

Fig. 4 Total population projections (a left) and the rate of change of this total population (b right) for three UK regions

population densities, they have similar population trajectories. This is due to the relatively even representation of each age group within the NUTS-2. Conversely, UKI1 has a distinctly different population trajectory due to its characteristically young population: age groups which experience slower rates of change within the SSP1 scenario.

\section{Urbanisation trends (artificial surface demand)}

Within RUG, the changes in regional population structure, when linked to residential preferences, drive (i) the artificial surface types where different age groups prefer to reside and (ii) the artificial surface changes required to adequately support the population of the region. As a consequence, the magnitude of future artificial surface expansion within Europe is also highly dependent upon the socioeconomic scenario being considered, which is linked to the population projection (Fig. $5)$.

If societal preferences (where people chose to live) and spatial planning (as a controller of housing density) were to remain unchanged from the current situation, the changing size and demographic structure of Europe's population, as described by the population downscaling approach, are estimated to result in artificial surface expansion constituting up to $6 \%$ of the European land area by 2100 (Fig. 5a). Reflecting the SSP-specific population trends, population-driven artificial surface expansion is focused in SSP1 and SSP5, with insufficient demographic/overall population change predicted in SSP3 and SSP4 to drive significant artificial surface growth.

The inclusion of the socioeconomic change, for example increasing/decreasing population densities (reflecting spatial planning regulations), and societal residential preference, as described in the SSPs, significantly influences the observed urbanisation trends (Fig. 5b). Within both SSP3 and, to a greater extent, SSP5, artificial surface expansion is magnified as the population moves towards more expansive residential types. In SSP5, for example, sprawling development is a consequence of a wealthy population seeking larger suburban/ rural dwellings in less densely populated areas. By contrast, population-driven artificial surface expansion is controlled within SSP1 by an 'environment-friendly' society becoming more urbanised and residing in compact, densely populated, green-cities.

Broad-scale European trends in future artificial surfaces (Fig. 5b), as modelled by RUG, follow the expected socioeconomic response of each SSP. However, RUG also allows an exploration of regional- (NUTS-2) and local (10' grid cell)scale variability in projected outcomes. At the finest $\left(10^{\prime}\right)$ modelling resolution, increased regional and national variability in the spatial patterns of artificial surface change projected to 2100 become evident (Fig. 6). For example, a clear distinction exists, particularly under SSP5, in the modelling outcomes of the majority of European countries and the lowfertility countries (BG, HR, LT, LV, MT, RO): these have no substantive artificial surface expansion when compared to the significant urban sprawl projected elsewhere.

An advantage of integrating regional, age group-specific change into the RUG model is that it allows estimation of both (i) the magnitude (Fig. 6) and compositional changes (Fig. A8a) of future artificial surfaces and (ii) the population residing within them (Fig. A8b, annex). For example, the artificial surface expansion, to $\sim 9 \%$ of the European land area in SSP5, was attributed to an increasing population and shift in preference towards more expansive (and lower density) residential types. This residential preference shift is clearly evident in the projected artificial surface profile of the scenario that is primarily constructed of suburban/town (36\%) and rural (38\%) areas by 2100 (Fig. A8a). This represents a substantive change in the overall profile of European artificial surfaces, as driven by the largest (between SSP) change in the residential structure of the population with a substantial decrease in the proportion of the population resident in cities (declining to $18 \%$ of the population) and increasingly suburban (36\%)/rural 

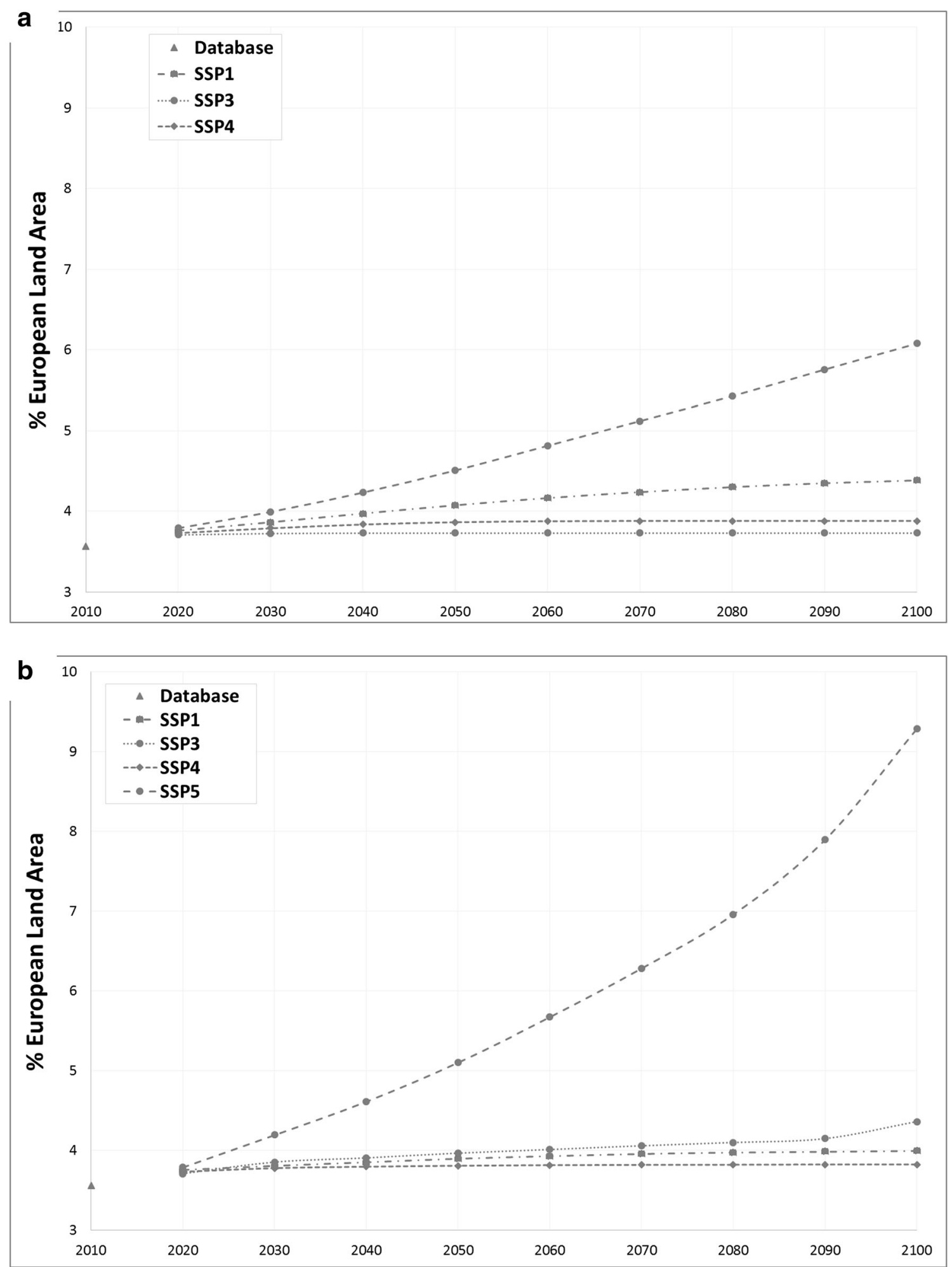

Fig. 5 Pan-European artificial surface expansion driven by $\mathbf{a}$ demographic change only and $\mathbf{b}$ demographic and societal change as defined under four socioeconomic scenarios

(46\%) population. A declining city-based population could lead to the abandonment of buildings and associated social issues or, given the increasing societal wealth of this scenario, the development of increased urban green space. It is in this context that comparing and contrasting the residential characteristics of the population in each of the socioeconomic scenarios (Fig. A8b) is an important parameter in informing, for example, social policies. 


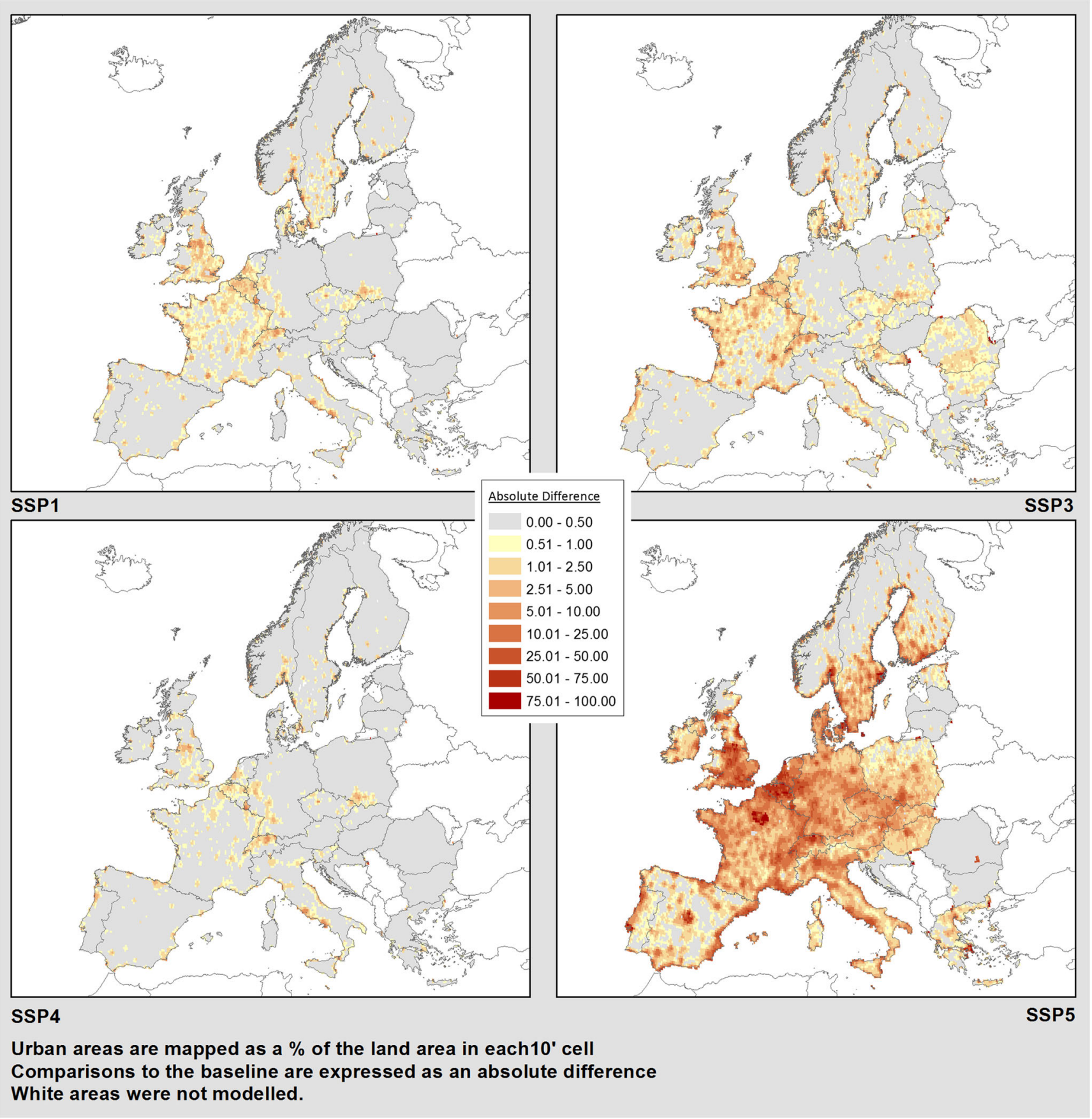

Fig. 6 The projected change, from baseline, in artificial surface extent (as a percentage of the $10^{\prime}$ cell land area) by 2100 under four different socioeconomic scenarios. Darker colours are associated with greater artificial surface expansion

\section{Discussion}

This work has demonstrated an approach to improve upon modelling frameworks that only use total population and/or where population change is uniformly distributed across a country. Value has been added by (i) increasing the thematic resolution of the population to age groups, (ii) demonstrating the change in population growth patterns caused by age specificity, (iii) demonstrating that total population change is regionally variable and (iv) illustrating the resultant effects upon urbanisation trends across Europe.

Population structure is regionally variable and, as such, should be considered in spatially explicit modelling where population is a key input. If it were assumed that all age groups were evenly distributed (at a regional, NUTS-2 scale) across a given country, then the application of uniform, age group-specific population change would result in, for a given time-step, (i) all regions having the same relative change in 
their total population; (ii) the relative contribution of any region, to the country's overall population remaining unchanged and (iii) the rate of change in the total population, to the current time-step, being the same for all regions. However, as the results show (cf. Fig. A7), this circumstance is rare for European countries. Population trends are country specific, with some more evenly distributed than others. The population structure at the baseline has a significant influence on the regional variability of population dynamics over time: for example, in Germany, age groups are relatively evenly distributed at a regional scale, and hence, variability in total population change is small, whereas in Spain, greater regional variability, due to the uneven distribution of age-groups, is observed. Our results have demonstrated that with the age- and SSP-specific population projections, even if the age-specific rates of change are uniform across all regions within a country, the total population and rate of change (between time-steps) is region specific due to regions differing (baseline) demographic profiles.

The results (Fig. 5) demonstrate that changing populations alone can drive artificial surface expansion. However, the predicted urbanisation outcomes do not fully reflect the environmental, societal and political circumstances, described by the full SSP storylines, nor the implications these factors might have upon future urbanisation. The parameterisation of RUG according to the SSP storylines (Fig. A5, annex) captures these broader societal changes providing estimates of future artificial demand as a function of (i) the changing demographics (and size) of the population, (ii) the changing residential preferences of this population and (iii) the strength/form of future planning legislation.

Life cycle stage (here: age) is a key determinant of an individual's residential preferences. The increased thematic resolution of demographic information, provided by age-groups, enables the modelling of different residential types as the relationship between different age groups and their residential preferences can be estimated. The impact of considering both demographic change and changing socioeconomic characteristics (in the form of societal preferences and spatial planning regulations) is visible in Fig. 5b. Residential types differ (both within and between scenarios), in terms of their housing densities, environmental characteristics (noise, air pollution), green-space provision and/or infrastructure. Equally, residential types are a broad-scale indicator of access to social services such as (but not exclusively) education and health-care. For example, the environment-friendly urban centres of SSP1 will differ significantly from the declining wealth and social fragmentation highlighted in SSP3. The higher density urban areas in SSP1 are typically considered advantageous in terms of ensuring future service provision, transport efficiencies and sustainable development (EU
2011). The provision of the demographic profile of residential areas by RUG and supported by the population downscaling therefore provides important tools to explore both the projected spatial distribution and residential circumstances of future populations: key determinants in informing/exploring urban, social and environmental policy.

Artificial surface expansion, in particular the sprawling trend of SSP5 from $\sim 3$ to $\sim 9 \%$ of the European land area, will exacerbate land competition with the agriculture and forestry sectors, leading to an increasingly urbanised population having to balance the ability to meet demand in terms of food and resource supply. However, an internal distinction in Europe is visible in Fig. 6 where several countries (Bulgaria, Romania, Latvia, Lithuania) no longer follow the main trend in SSP5 of significant increases in urban development and sprawl. This can be linked to the division of countries into low fertility and rich-OECD and their associated demographic (mortality, fertility and migration) assumptions (KC and Lutz 2014). For example, Romania is not projected to have the significant increases in population associated with SSP5 in the remainder of Europe. Instead, like the other low-fertility countries, it is characterised by an ageing but overall decreasing population. As a consequence of this trend, RUG model outcomes indicate that the population could be housed within the existing artificial surface footprint (although the housing stock may change) limiting urban sprawl. Such trends demonstrate the link between the underlying population modelling and artificial surface outcomes.

In conclusion, increased thematic detail in terms of both the artificial surface types and demographics allows us to (i) incorporate population change into the modelling of land use change, which is important given the predominantly ageing population profiles of Europe; (ii) increase the thematic detail of modelling outcomes in terms of both future populations (age groups) and artificial surface structures (residential types) and (iii) enable linkages between population, residential preferences and urbanisation outcomes. By combining population downscaling and the RUG model, projected outcomes allow integration of the structure of future artificial surfaces and the demographic profiles of the population they contain. This information is important in understanding urbanisation trends but also supports the exploration of the implications of these trends for human well-being and land use more broadly.

Open Access This article is distributed under the terms of the Creative Commons Attribution 4.0 International License (http:// creativecommons.org/licenses/by/4.0/), which permits unrestricted use, distribution, and reproduction in any medium, provided you give appropriate credit to the original author(s) and the source, provide a link to the Creative Commons license, and indicate if changes were made. 


\section{References}

Absar SM, Preston BL (2015) Extending the shared socioeconomic pathways for sub-national impacts, adaptation, and vulnerability studies. Glob Environ Chang 33:83-96. doi:10.1016/j.gloenvcha.2015.04. 004

Bongaarts J, Bulatao RA, Eds (2000) Beyond six billion: forecasting the world's population. National Academies Press

Carter TR, Fronzek S, Inkinen A, Lahtinen I, Lahtinen M, Mela H, O’Brien KL, Rosentrater LD, Ruuhela R, Simonsson L, Terama E (2016) Characterising vulnerability of the elderly to climate change in the Nordic region. Reg Environ Chang 16(1):43-58. doi:10.1007/ s10113-014-0688-7Cohen JE (2003) Human population: the next half century. Science 302(5648):1172-1175. doi:10.1126/science. 1088665

EU (2011) Cities of tomorrow: challenges, visions, ways forward. European Union Regional Policy, European Union

Eurostat (2016a). Degree of urbanisation database (degurb). (http://ec. europa.eu/eurostat/web/degree-of-urbanisation/data/database). Eurostat. (Accessed: July 2016)

Eurostat (2016b). Live births by mother's age and NUTS2 region database (demo_r_fagec). (http://ec.europa.eu/eurostat/web/regions/ data/database). Eurostat. (Accessed: July 2016)

Eurostat (2015) Population on 1 January by five years age group, sex and NUTS 2 region [demo_r_pjangroup] http://appsso.eurostat.ec. europa.eu/nui/show.do?dataset=demo_r_pjangroup\&lang=en. Accessed 29.6.2016

Fontaine CM, Rounsevell MDA (2009) An agent-based approach to model future residential pressure on a regional landscape. Landsc Ecol 24:1237. doi:10.1007/s10980-009-9378-0

Fontaine CM, Rounsevell MDA, Barbette AC (2014) Locating household profiles in a polycentric region to refine the inputs to an agentbased model of residential mobility. Environment \& Planning B 41: 163-184. doi:10.1068/b37072

Harrison PA, Holman IP, Cojocaru G, Kok K, Kontogianni A, Metzger MJ, Gramberger M (2013) Combining qualitative and quantitative understanding for exploring cross-sectoral climate change impacts, adaptation and vulnerability in Europe. Reg Environ Chang 13:761780. doi:10.1007/s10113-012-0361-y

IIASA (2012) SSP database, 2012-2015, International Institute for Applied Systems Analysis. https://ntcat.Iiasa.Ac.At/SspDb. Accessed 19.9.2016

Jones RN, Patwardhan A, Cohen S, Dessai S, Lammel A, Lempert R, Mirza MQ, von Storch H (2014) Foundations for decision making in Climate Change 2014: impacts, adaptation, and vulnerability. Part A: global and sectoral aspects. Contribution of working group II to the fifth assessment report of the intergovernmental panel on climate change, Cambridge University press, Cambridge, United Kingdom and New York, NY, USA

KC S, Lutz W (2014) The human core of the shared socioeconomic pathways: population scenarios by age, sex and level of education for all countries to 2100. Glob Environ Chang 42:181-192. doi:10. 1016/j.gloenvcha.2014.06.004

Kok K, Pedde S (2016) IMPRESSIONS socio-economic scenarios. EU FP7 IMPRESSIONS Deliverable D2:2

Kriegler E, O'Neill BC, Hallegatte S, Kram T, Lempert RJ, Moss RH, Wilbanks T (2012) The need for and use of socioeconomic scenarios for climate change analysis: a new approach based on shared socioeconomic pathways. Glob Environ Change 22:807-822. doi:10. 1016/j.gloenvcha.2012.05.005

Lambin EF, Meyfroidt P (2010) Land use transitions: socio-ecological feedback versus socioeconomic change. Land Use Policy 27(2): 108-118. doi:10.1016/j.landusepol.2009.09.003
Moss RH, Edmonds JA, Hibbard KA, Manning MR, Rose SK, van Vuuren DP, Carter TR, Emori S, Kainuma M, Kram T (2010) The next generation of scenarios for climate change research and assessment. Nature 463:747-756. doi:10.1038/ nature 08823

O’Neill BC, Kriegler E, Ebi KL, Kemp-Benedict E, Riahi K, Rothman DS, van Ruijven BJ, van Vuuren DP, Birkmann J, Kok K, Levy M, Solecki W (2015) The roads ahead: narratives for shared socioeconomic pathways describing world futures in the 21st century. Global Environmental Change (in press). doi:10.1016/j.gloenvcha.2015.01. 004

O’Neill BC, Kriegler E, Riahi K, Ebi KL, Hallegatte S, Carter TR, Mathur R, van Vuuren DP (2014) A new scenario framework for climate change research: the concept of shared socioeconomic pathways. Clim Chang 122:387-400. doi:10.1007/s10584-013-0905-2

Reginster I, Rounsevell MDA (2006) Future scenarios of urban land use in Europe. Environment and Planning B: Planning and Design 33(4):619-636. doi:10.1068/b31079

Riebsame WE, Meyer WB, Turner BL (1994) Clim Chang 28:45. doi:10. 1007/BF01094100

Rogers A (1986) Parameterized multistate population dynamics and projections. J Am Stat Assoc 81(393):48-61. doi:10.1080/01621459. 1986.10478237

Rounsevell MDA, Pedroli B, Erb K-H, Gramberger M, Gravsholt Busck A, Haberl H, Kristensen S, Kuemmerle T, Lavorel S, Lindner M, Lotze-Campen H, Metzger MJ, Murray-Rust D, Popp A, PérezSoba M, Reenberg A, Vadineanu A, Verburg PH, Wolfslehner B (2012) Challenges in land system science. Land Use Policy 29: 899-910. doi:10.1016/j.landusepol.2012.01.007

Rounsevell MDA, Arneth A, Alexander P, Brown DG, de NobletDucoudré N, Ellis E, Finnigan J, Galvin K, Grigg N, Harman I, Lennox J, Magliocca N, Parker DC, O'Neill BC, Verburg PH, Young O (2014) Towards decision-based global land use models for improved understanding of the earth system. Earth System Dynamics 5:117-137. doi:10.5194/esd-5-1172014

United Nations (2014) Department of economic and social affairs, population division. World Urbanization Prospects: The 2014 Revision, custom data acquired via website

Van Ruijven B, Levy MA, Agrawal A, Biermann F, Birkmann J, Carter TR, Ebi KL, Garschagen M, Jones B, Jones R, Kemp-Benedict E, Kok M, Kok K, Lemos MC, Lucas PL, Orlove B, Pachauri S, Parris TM, Patwardhan A, Petersen A, Preston BL, Ribot J, Rothman DS, Schweizer VJ (2014) Enhancing the relevance of shared socioeconomic pathways for climate change impacts, adaptation and vulnerability research. Clim Chang 122:481-494. doi:10.1007/s10584013-0931-0

Veldkamp A, Verburg P, Kok K, de Koning GHJ, Priess J, Bergsma AR (2001) The need for scale sensitive approaches in spatially explicit land use change modeling. Environmental Modeling \& Assessment 6:111. doi:10.1023/A:1011572301150

Verburg PH, Schot PP, Dijst MJ, Veldkamp A (2004) Land use change modelling: current practice and research priorities. Geo Journal 61(4):309-324. doi:10.1007/s10708-004-4946-y

van Vuuren DP, Carter TR (2014) Climate and socioeconomic scenarios for climate change research and assessment: reconciling the new with the old. Clim Chang 122(3):415-429. doi:10.1007/s10584013-0974-2

Wittgenstein Centre (2015) Wittgenstein Centre for Demography and Global Human Capital. Wittgenstein Centre Data Explorer Version 1.2. http://www.wittgensteincentre.org/dataexplorer. Accessed 19.9. 2016 